\title{
EL CRUCIFICADO DE LA SANGRE: OBRA DE MARTÍN ALONSO DE MESA EN LIMA
}

\author{
THE CRUCIFIED OF THE BLOOD: A WORK BY \\ MARTÍN ALONSO DE MESA IN LIMA
}

\author{
Rafael Ramos Sosa \\ Universidad de Sevilla. España \\ rabel@us.es
}

\begin{abstract}
Se da a conocer una nueva escultura de Martín Alonso de Mesa en Lima. En el proceso de restauración del Crucificado de la Sangre, se encontró en su interior un pergamino con los nombres del escultor y el comitente y la fecha de realización.

Palabras clave: Crucificado; escultura; Perú; Sevilla; siglo XVII.
\end{abstract}

We publish a new sculpture of Martín Alonso de Mesa in Lima. A parchment with the names of the sculptor and the sponsor and the date of realization was found inside the Crucified of the Blood during the process of restoration.

Keywords: Crucified; sculpture; Peru; Seville; $17^{\text {th }}$ century.

El conocimiento sobre la escultura limeña ha avanzado sustancialmente en los últimos lustros, sobre todo en la primera mitad del siglo XVII, con la aclaración de las personalidades artísticas de los escultores sevillanos emigrados al Perú en estos años. Uno de los mejor conocidos y con obra identificada es Martín Alonso de Mesa $^{1}$. En estas páginas se da a conocer una nueva escultura de su mano, firmada y datada, por tanto una obra sobre la que puede conocerse mejor su estilo, trayectoria y la evolución general del arte de la talla en el extenso virreinato peruano.

${ }^{1}$ SAN CRISTÓBAL, Antonio: "Martín Alonso de Mesa y Juan García Salguero en el retablo mayor de la Concepción”, Revista del Archivo General de la Nación, 17, 1998, pp. 91-130; RAMOS SOSA, Rafael: "Martín Alonso de Mesa, escultor y ensamblador (Sevilla, c. 1573-Lima, 1626)", Anales del Museo de América, 8, 2000, pp. 45-63; y RAMOS SOSA, Rafael: "Una escultura de Martín Alonso de Mesa, el San Juan Evangelista de la Catedral de Lima (1623) y otras noticias”, Histórica, XXVII-1, 2003, pp. 181-206. 
Recientemente se ha ejecutado la restauración de un Crucificado que presidía el retablo mayor del templo de Santo Domingo de Lima (Figura 1). En la intervención pudo comprobarse que la escultura hueca guardaba en su interior un pergamino, donde constaban escritos con tinta los nombres del escultor, el comitente y la fecha del encargo (Figura 2). Dice así: "Este Sancto Crucifixo es de mano de Martín Alonso de mesa escultor acabole el mes de Março de 1619. hizole por mdo del Pe fr Saluador Ramirez Por de este conuento del Rosario de Lima el qual supca a nro señor se sirua de perdonarle sus pecados y lo mismo ruega por todos" 2 .

La restauración del Crucificado dominico ha resultado peculiar ya que se le ha querido otorgar una nueva advocación: "de la sangre", y tras limpiar los repintes históricos ha sido objeto de unos espurios y abusivos chorreones de sangre que desfiguran la imagen (Figura 3). Buen ejemplo contemporáneo de las coyunturas artísticas entre propietario, restaurador, religiosidad y piedad en las que se sigue debatiendo la imagen de devoción (Figura 4).

Tras el hallazgo documental en el interior del Cristo de la Sangre de Santo Domingo, parece confirmarse la identificación y atribución razonada con apoyo documental realizada sobre el Crucificado de la Vera Cruz, en Santiago de Chile, obra de Martín Alonso por su directa relación formal y estilística ${ }^{3}$. También habría que mirar con nuevos ojos el conocido Cristo de la Conquista del templo de la Merced en Lima, y tal vez identificarlo como el citado documentalmente en la capilla de redención de cautivos en 1620, hoy en un pilar del crucero ${ }^{4}$. Este crucificado mercedario está más transformado en su rostro y paño de pureza, pero parece en la misma línea que estos comentados, con la particularidad iconográfica muy sevillana de presentar cuatro clavos, cruzados los pies en la misma posición del de la Clemencia de Montañés. Sin duda se trata de una escultura del siglo XVII que pudiera fecharse entre 1610 y 1620.

Martín Alonso de Mesa, escultor sevillano emigrado al Perú a comienzos del siglo XVII, dominó durante dos décadas la contratación de los principales retablos y esculturas de la ciudad hasta que murió en 1626. De sus años sevillanos se conserva la Virgen de la Oliva en Vejer de la Frontera (Cádiz). En Lima se han identificado con seguridad algunas obras entre las que destacan el San Juan Evangelista de la catedral (1623) y ahora este Crucificado de la Sangre. La interpretación que ofrece Martín Alonso va inserta en el clasicismo y decoro propio de la escuela hispalense de la época, como puede apreciarse en la caja torácica de modelos aun atléticos, junto a una clara inspiración naturalista buscando

${ }^{2}$ El pergamino mide $17 \times 36 \mathrm{~cm}$. Agradezco al taller de restauración de don Manuel Palma Oquendo y a Raúl Palma las facilidades para ver y fotografiar esta escultura en 2014 y 2015.

3 RAMOS SOSA, Rafael: "La proyección de los talleres limeños de escultura y retablo en el reino de Chile (1603-1668)", en Arte y Crisis en Iberoamérica. Santiago de Chile, 2004, pp. 41-47.

${ }^{4}$ BARRIGA, Víctor: El templo de la Merced de Lima. Arequipa, 1944, pp. 16-17 y 92. 
efectos más vivos y cercanos al espectador. El paño de pureza muestra una moña y caída lateral de ahuecados pliegues y movidas curvas, de concepto más barroco que la anatomía del Cristo. Precisamente en Santo Domingo quiso el escultor ser enterrado, en la capilla del Rosario de los españoles, ya que fue hermano veinticuatro de la cofradía de la Virgen.

Menos conocido en el contexto artístico limeño es el prior fray Salvador Ramírez. El cronista fray Juan Meléndez nos ofrece una sustanciosa biografía en su clásica e imprescindible obra. Nació en Arequipa en 1575; sus padres Francisco Ramírez y Ana de Saldivar -viendo su inclinación a la piedad y la oración- lo enviaron a Lima para su mejor formación, donde comenzó a frecuentar la iglesia de Santo Domingo. Terminó por ingresar en la orden dominica y profesó en 1591.

Fue prior de varios conventos, vicario general en dos ocasiones y provincial. En el convento de Santo Domingo ejerció de prior en 1618 y 1625. Falleció en Lima el 2 de diciembre de 1627. Meléndez lo calificaba de "varón verdaderamente apostólico de mucha oración, penitencia, pobreza, caridad, y paciencia singularísima en los trabajos..." Cuando fue prior del convento del Rosario de Lima procuró embellecerlo y precisamente Meléndez ya nos avisaba que encargó un Crucificado en el que había depositado por escrito "una petición de su alma". Así nos lo cuenta el cronista dominico: "Hizo muchas obras en este Convento... aquella famosa Imagen de escultura al natural, del mismo Cristo bien nuestro Crucificado en la Cruz, que está en la Capilla de San Gerónimo de los Aliagas, es obra del celo, y la devoción de nuestro grande Prior, el Presentado Fray Salvador Ramírez; y en el pecho de la Imagen, hizo hiciesen una concavidad, y en ella puso un papel escrito, y firmado de su letra, cerrado, y sellado, que nunca se ha sabido, lo que contiene, por haberse cubierto y embarnizado la superficie, y no atreverse ninguno a romper el secreto, por no romper el pecho de la Imagen, de quien le quiso fiar este devoto Prelado: que claro está contendrá algún afecto, ó petición de su alma, en orden a la felicidad de su salvación, pues no se puede entender, que un hombre tan espiritual, como era el Padre Fray Salvador, depositase en el pecho de la Imagen, lo que no se pudiera registrar por los ojos del original" . En el proceso de restauración la cavidad apareció en la parte dorsal, no en el pecho. El cronista añade un dato importante a la hora de seguir las transformaciones internas de la iglesia y la localización de pinturas y esculturas: la imagen citada estaba en la capilla de los Aliaga, es decir, la de San Jerónimo.

Las tareas y gustos artísticos de fray Salvador Ramírez no acabaron en este encargo expiatorio ${ }^{7}$; el mismo cronista nos cuenta que siendo prior del convento por segunda vez (1625) realizó un nuevo requerimiento a otro escultor sevillano: "En este tiempo hizo hacer las dos Ymágenes de escultura de Nuestro Padre Santo Domingo, y Santo Thomas de Aquino de lo más primoroso, que hay en Lima, y que pudieran envidiarse mucho en Europa, y aun en Roma, entre sus valientes estatuas de mármol: son de mano del famoso

${ }^{5}$ MELÉNDEZ, Fray Juan: Tesoros verdaderos de las Yndias. T. I. Roma, 1681, p. 609. Le dedica los capítulos XIX y XX en el tomo tercero de su crónica.

${ }^{6}$ Ibidem, t. III, p. 130.

7 FREEDBERG, David: El poder de las imágenes. Madrid, 1992, pp. 169 y ss. 


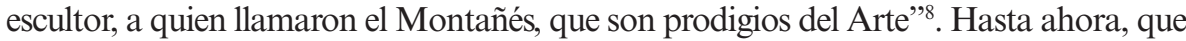
se sepa, no se han identificado estas esculturas, o tal vez desaparecieron con los continuos y pavorosos seísmos de la ciudad, transformaciones y reconstrucciones posteriores.

Ramírez fue uno de los dominicos que protagonizaron y sufrieron el enfrentamiento entre peninsulares y criollos por el control de los cargos de gobierno en las provincias religiosas americanas. $\mathrm{Al}$ parecer los dominicos fueron pioneros en esta pugna en el virreinato del Perú, que ganaron desde muy pronto en el denominado "primer criollismo conventual peruano".

Esta escultura no debe dejar de verse en un contexto más amplio de tipo religioso, pero también histórico y social hispanoamericano, como fueron las tensiones en el seno de las órdenes religiosas a la hora de ejercer los cargos de gobierno, prolongación de las pugnas de americanos y españoles en la esfera civil. Confrontaciones que derivaron a veces en choques violentos y en los que es posible vislumbrar también las contradicciones, sufrimientos y ofensas personales de aquellos frailes que, dedicados públicamente a la predicación de la fe y ejercicio de la caridad, se dejaron llevar por banderías humanas. En fechas anteriores y cercanas al encargo de la escultura, fray Salvador fue encarcelado y expulsado de la ciudad por el virrey príncipe de Esquilache - que defendía venalmente sus propios intereses y al bando peninsular- ${ }^{10}$.

El contrito y escueto texto del pergamino resulta más que interesante al constatar el encargo de la escultura por fray Salvador, prior del convento en ese momento, como petición de perdonar sus pecados y los de todos. Podría verse aquí el carácter votivo de la imagen, una ofrenda implorando perdón. Junto al interés de estudiar la actitud interna del artista frente a su obra, ahora puede hacerse hincapié sobre la intención y respuesta interior del comitente ante la escultura que encargó, atisbar esas reverberaciones de la relación entre imagen sagrada y creyente, sobre todo si se alcanzan altas cotas artísticas y estéticas. Constituye un ejemplo muy conocido y poco desgranado el soberbio Crucificado de la Clemencia y el arrepentido arcediano de Carmona, don Mateo Vázquez de Leca ${ }^{11}$. La escultura fue metáfora de la plegaria, intercesora ante Dios y moneda de redención.

Fecha de recepción: 30 de septiembre de 2016

Fecha de aceptación: 20 de enero de 2017

${ }^{8}$ MELÉNDEZ, F. J.: Tesoros..., t. III, p. 136.

9 LAVALLÉ, Bernard: Las promesas ambiguas, criollismo colonial en los Andes. Lima, 1993, pp. 173 y 183-185.

10 TORRES ARANCIVIA, Eduardo: Corte de Virreyes, el entorno del poder en el Perú del siglo XVII. 2a ed., Lima, 2014, pp. 140-141 y 205-207.

${ }^{11}$ RAMOS SOSA, Rafael: "Un especialista en crucificados: la obra del escultor Bernardo Pérez de Robles en Arequipa”, Laboratorio de Arte, 12, 1999, pp. 153-162; y GÓMEZ PIÑOL, Emilio: "Cristo del Auxilio", en RAMOS SOSA, Rafael y BOGDANOVICH, Luis Martín: La madera hecha Dios: arte fe y devoción en torno a la pasión de Cristo. Lima, 2016, p. 81. 


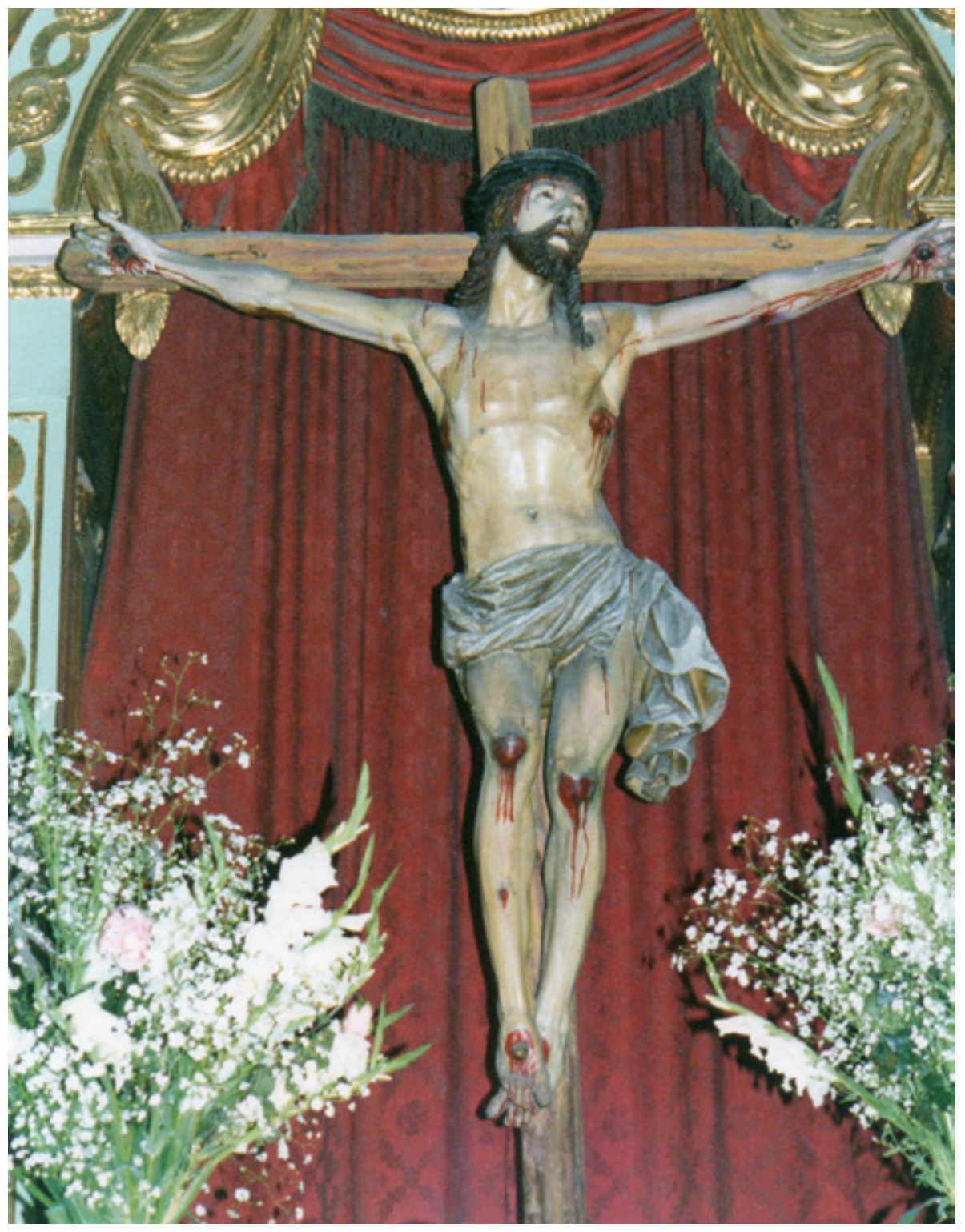

Figura 1. Martín Alonso de Mesa, Crucificado de la Sangre antes de la restauración, 1619, iglesia de Santo Domingo, Lima. Foto: Rafael Ramos Sosa. 


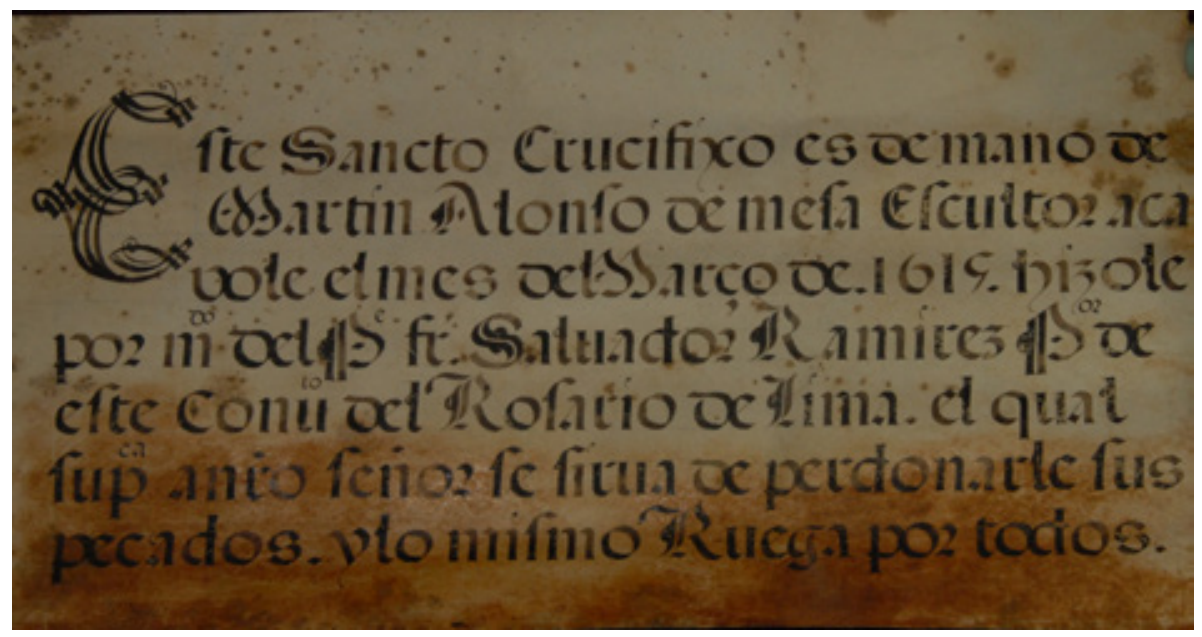

Figura 2. Pergamino con los nombres del escultor y el comitente y la fecha del fin de la obra. Foto: Rafael Ramos Sosa. 


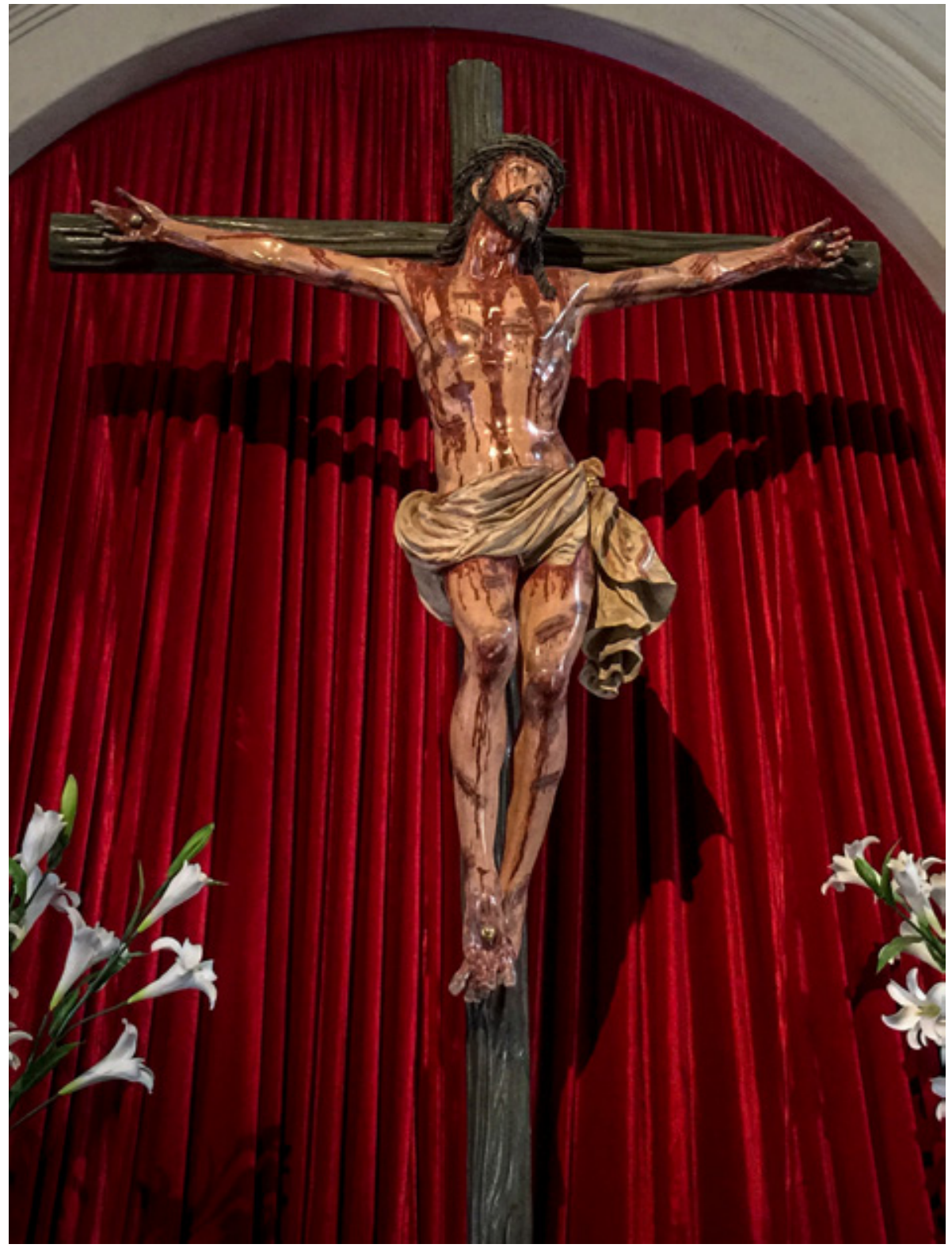

Figura 3. Martín Alonso de Mesa, Crucificado de la Sangre, después de la restauración, 1619, iglesia de Santo Domingo, Lima. Foto: Juan Manuel Parra. 


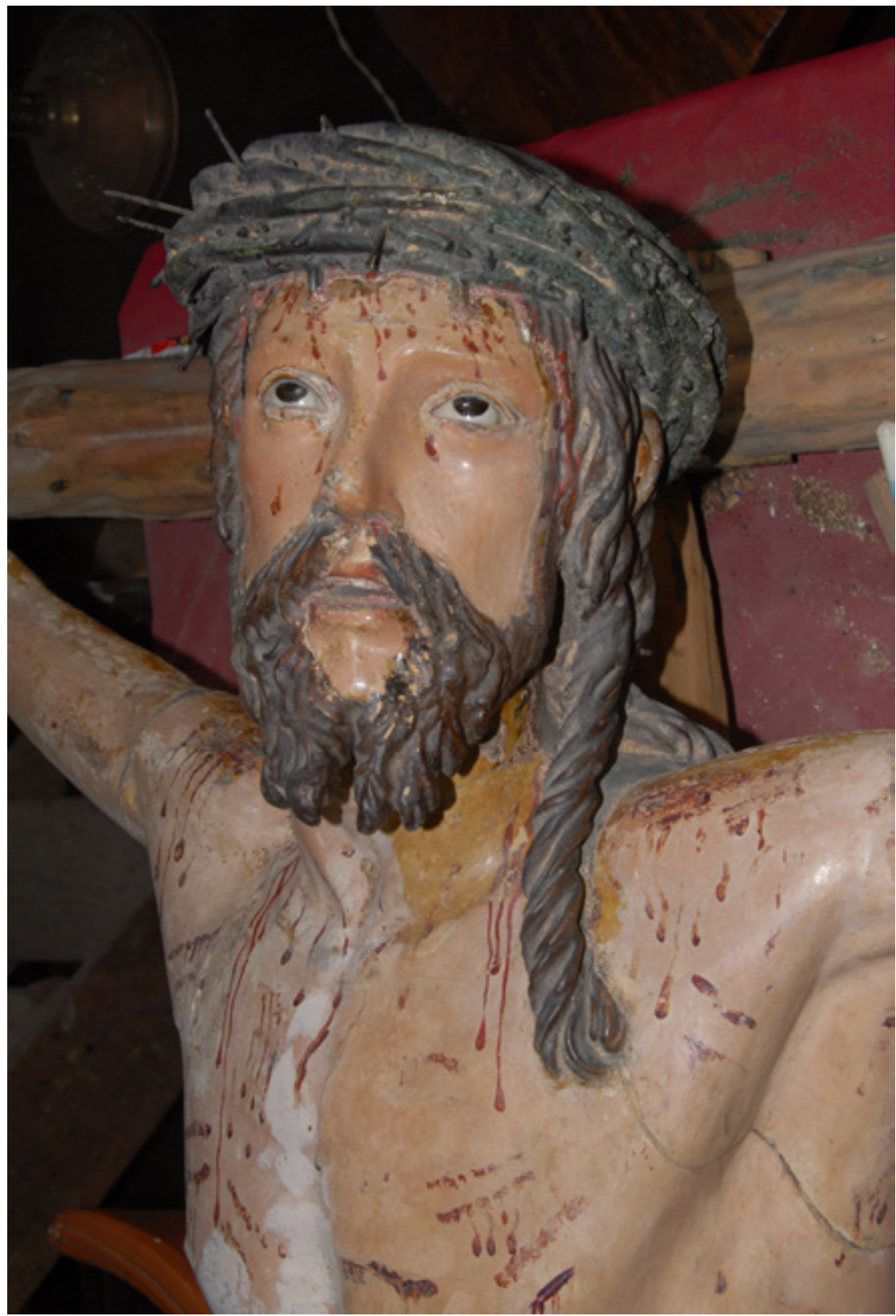

Figura 4. Martín Alonso de Mesa, Crucificado de la Sangre, detalle del rostro en proceso de limpieza, 1619, iglesia de Santo Domingo, Lima. Foto: Rafael Ramos Sosa. 